\title{
Interface characteristics in cemented carbides with alternative binders
}

\author{
Z. Roulon, S. Lay, J. M Missiaen
}

Univ. Grenoble Alpes, CNRS, Grenoble INP, SIMAP, 38000 Grenoble, France

S. Lay : https://orcid.org/0000-0001-9790-8282

J. M. Missiaen: https://orcid.org/0000-0002-1318-4772

Corresponding author: S. Lay (sabine.lay@simap.grenoble-inp.fr)

\section{Abstract}

Cemented tungsten carbides with $\mathrm{Co}$, Ni or Fe binders were studied by transmission electron microscopy. Particular attention was paid to phase and grain boundaries. A striking feature is the high frequency of coherent carbide/binder interfaces with Fe. The Fe rich binder adopts an epitaxy orientation relationship with prismatic facets of WC, with a parametric misfit of about 1.5\%. A special orientation relationship with basal facets of WC grains is sometimes observed with Ni binder, as already noticed for Co. It is associated with a parametric misfit of about 15\%. Binder segregation in WC grain boundaries was studied taking into account the effect of carbon content in the alloys. Whatever the binder, no influence of the carbon content could be pointed out. The analyses performed in random grain boundaries in WC-Co alloys agree with the literature value of 0.5 monolayer of segregated Co while slightly larger values are obtained for $\mathrm{Ni}$ and Fe binder. $\sum=2$ special grain boundaries were studied in WC-Co and WC-Ni alloys and no segregation was detected. The higher grain boundary segregation as well as the occurrence of coherent interfaces should influence the mechanical properties of WC-Fe alloys.

\section{Keywords}

Cemented carbides, grain boundary segregation, coherent interfaces, Ni and Fe binders

\section{Introduction}

WC-Co cemented carbides are widely used in a number of applications where high wear resistance, hardness and toughness are required as in tooling, mining or construction industry. In applications where corrosion or oxidation resistance are required, WC-Ni alloys were shown to have better properties than WC-Co and mainly WC-NiCr alloys were developed for this purpose [1,2]. Due to the recent European Community Regulation on chemicals and their safe use, Co should be avoided and alternative binders were considered for some applications as Ni-Fe-Co alloys [3,4]. The interest for such alloys was however early pointed out [5-7] and several works were dedicated to phase diagram calculations [8-11]. Only recently, physical properties of cemented carbides with alternative binder such as Ni-based alloys, stainless steel or Fe-Ni-Co alloys were investigated e.g. [11-15]. Suitable compositions have to be carefully examined to avoid the formation of detrimental phases $[16,17]$. Up to now, there has been little research on the exact effect of $\mathrm{Ni}$ - or Fe- rich binder on sintering and microstructure evolution [18,19]. 
Properties of cemented carbides depend on the strength of the binder and carbide phases as well as the strength of carbide/carbide grain boundaries and carbide/binder interfaces $[20,22]$. Indeed the performance of the alloys is closely related to the existence of a carbide skeleton across the material and grain boundaries are constituents of the carbide skeleton. For cobalt binder, calculations using the density functional theory (DFT) predict that half a monolayer $(0.5 \mathrm{ML})$ of cobalt segregates at grain boundaries, which decreases their energy and prevents the complete infiltration during sintering [23]. Experimental investigations by energy dispersive X-ray spectroscopy (EDS) in transmission electron microscopy (TEM) confirmed the presence of cobalt in grain boundaries [24]. While a segregation layer with a thickness range of 1-2 $\mathrm{nm}$ was observed in some grain boundaries by high resolution transmission electron microscopy [25], investigations carried out by TEM/EDS with high spatial resolution or by atom probe tomography (APT) concluded to a segregation of $0.5-1$ $M L$ of cobalt, which confirms the atomistic calculations $[26,28]$. There is no consensus that cobalt content depends on the boundary plane orientation $[25,29]$. Carbon content in the alloy would however affect the composition of grain boundaries, and higher segregation would occur in grain boundaries of tungsten-rich alloys [30]. Recent calculations also predict that nickel should segregate as $0.5 \mathrm{ML}$ in grain boundaries while no experimental data are available yet [31]. For iron, no data at all exist in the literature on that point.

Carbide/binder interface structure and energy are also important parameters to consider as they influence the wettability of the carbide phase by the binder, the sintering process as well as the strength of interfaces $[23,32]$. Lattice coherency at interfaces also seems an important feature that would improve the strength of the alloy [33]. While epitaxy orientations at carbide/cobalt interfaces were experimentally and theoretically studied [34,35], no data exist for nickel and iron. More generally, few detailed analyses of the microstructure of the basic WC-Ni or WC-Fe cemented carbides after sintering are available, especially the effect of carbon content was little investigated [18,19].

In this study, a special attention is given to carbide/binder interfaces and WC/WC grain boundaries in cemented carbides with iron and nickel binders, as well as with cobalt binder for comparison. The grain shape as well as epitaxy relationships occurring at carbide/binder interfaces were studied by TEM. The grain boundary segregation was investigated using elemental mapping in a scanning transmission electron microscope. The influence of carbon content was also determined.

\section{Experimental conditions}

\subsection{Sample preparation}

WC-20M (vol\%), M being Co, Ni or Fe, were prepared from pre-alloyed WC powder and raw metallic powder with a mean size from 2 to $8 \mu \mathrm{m}$ approximately. Milling step was proceeded by ball milling with cylindrical milling bodies, for approximately $43 \mathrm{~h}$ in ethanol. Then the mills were spray-dried and granulated in final particles with approximately 5 to $30 \mu \mathrm{m}$ diameter size. Samples were compacted in a $8 \mathrm{~mm}$ diameter cylindrical die to reach $55 \%$ green density. After debinding in $\mathrm{He}-\mathrm{H} 2$ atmosphere, sintering was performed in a SETARAM TMA92 dilatometer in $\mathrm{Ar}$ atmosphere, with a heating rate of $3^{\circ} \mathrm{C} / \mathrm{min}$, a sintering plateau at $1450{ }^{\circ} \mathrm{C}$ for $0.5 \mathrm{~h}$ 
and a cooling rate of $30^{\circ} \mathrm{C} / \mathrm{min}$. For each binder, two carbon contents were used to obtain a carbon-rich alloy lying in the (WC-M-C) 3-phase domain and a tungsten-rich one in the (WC-M-(W,M) 6 C) domain. Scanning electron microscopy observations confirm the presence of graphite in the C-rich alloys and of $(\mathrm{W}, \mathrm{M})_{6} \mathrm{C}$ phase in the $\mathrm{W}$-rich alloys [20]. These alloys are called WC-M,C and WC-M,W in the following. For TEM characterization, samples were grinded to a thickness of 20-40 $\mu \mathrm{m}$ and electron transparency was achieved by Ar ion milling.

\subsection{Microstructure characterization}

TEM microstructural studies were performed using a JEOL 3010 microscope. Analytical measurements were carried out by scanning transmission electron microscopy (STEM) using the 2100F JEOL microscope equipped with an EDS device. Especially the composition of WC/WC grain boundaries was explored. The binder content was investigated in six grain boundaries in WC-Co,C and WC-Co,W, five and four in WC-Ni,C and WC-Ni,W, respectively, five and eight in WC-Fe,C and WC-Fe,W, respectively. For all alloys except WC-Fe,W, STEM/EDS maps were acquired using a beam size of $0.7 \mathrm{~nm}$, a magnification of 500000 and a size map of $512 \times 512$ pixels so the pixel size in the map was about $0.7 \mathrm{~nm}$. For WC-Fe,W, a beam size of $1 \mathrm{~nm}$, a magnification of 400000 and a map size of $256 \times 256$ were used so the pixel size was $1.4 \mathrm{~nm}$. Owing to the resolution of the maps, segregation in the boundary can be detected but segregation layer thinner than a few nm cannot be directly measured on the map. To evaluate the segregation width, a small box including the boundary in the center is delimited in the acquired map (Fig. 1). The size of the layer can be deduced from the composition of the box assuming all the binder is concentrated at the boundary [36,37]

Most box sizes were 20-40 nm in width and 100-150 nm in length. Two or three measurements could be carried out for each grain boundary by selecting several boxes along the boundary in the map. Indeed, no binder atoms are expected to be in solution in WC $[27,38]$, however a signal is detected in WC grains, likely due to binder redeposition during the preparation of the thin foil upon Ar beam milling stage. Moreover, this surface deposition is not uniform on the thin foil surface and variation of binder intensity on WC grain surface is observed. Therefore, the amount of binder in the grain boundary was defined as the total amount of binder in the box minus the mean amount found in WC grains, in the immediate vicinity of the grain boundary. Only boundaries with the habit plane nearly parallel to the electron beam were used for the measurements in order to accurately select the box including the grain boundary and measure the amount of binder on the WC grain surface close to the boundary (Fig. 1). Assuming all binder atoms lie in the boundary, the layer size, e, is calculated taking into account the box dimensions:

$$
\mathrm{e}=\frac{l_{1} l_{2} r v(M)}{r L v(M)+n L v(W C)} \quad \text { with } \mathrm{r}=\frac{m}{w}
$$

where $\mathrm{m}$ and $\mathrm{w}$ are the atomic concentrations of $\mathrm{M}$ and $\mathrm{W}$ measured in the box, $\mathrm{I}_{1}$ and $\mathrm{I}_{2}$ are the width and the length of the box, $L$ is the length of the boundary in the box, $v(\mathrm{WC})$ and $v(\mathrm{M})$ are the volumes of one unit cell of WC or binder, respectively, and $\mathrm{n}$ is the number of atoms per unit cell of binder. For the calculations, the stable crystal lattice of Fe at sintering temperature was used, i.e. the face centered cubic (FCC) lattice $(a=0.362 \mathrm{~nm})$ 
as for $\mathrm{Co}(\mathrm{a}=0.354 \mathrm{~nm})$ and $\mathrm{Ni}(\mathrm{a}=0.352 \mathrm{~nm})$, so the parameter $\mathrm{n}$ is equal to 4 . Carbon was excluded from the analyses as the quantification of light elements is difficult by EDS [39].

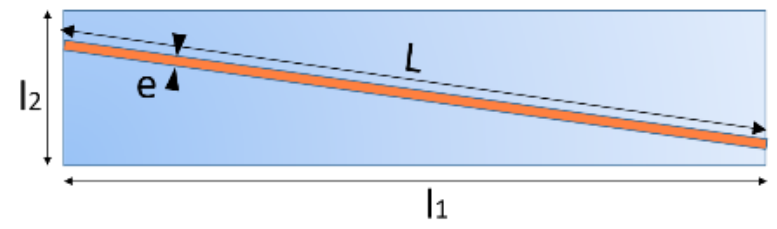

Figure 1: Drawing of the small box used for binder width evaluation in the grain boundary.

Moreover, quantitative analyses would require two types of corrections [39]. Firstly, composition standards should be used to correct Cliff-Lorimer factors of the EDS software, to transform the intensity signals into accurate relative concentrations. In addition, when the foil thickness increases, an absorption coefficient should be applied. This correction is tricky because it needs an accurate measurement of the foil thickness that is not easy to determine. So, in this study, rather thin areas of the TEM specimens were chosen for the analyses to minimize the absorption effect. For the quantification, the $M_{k}$ peak was used for cobalt and the $W_{M}$ peak for tungsten. Close values were found when $W_{L}$ or $W_{M}$ lines were chosen. To evaluate the validity of the measurements, the binder analyses were compared with compositions calculated by Thermocalc ${ }^{\mathrm{TM}}$ at $1000^{\circ} \mathrm{C}$, which are close to values after specimen cooling [40]. A rather good agreement was found, so no further correction was applied (Table 1). It is to notice that the layer width determined in this study is therefore not as reliable as values deduced from APT. However the comparison between the binders should be valid, owing to the neighboring position of $\mathrm{Co}, \mathrm{Ni}$ and $\mathrm{Fe}$ in the periodic table and to their close Ka peak energy. Moreover, thin foil thicknesses and instrumental analysis conditions were similar for all alloys.

\begin{tabular}{|l|l|l|}
\hline W/M (at\%) & WC-Ni,W & WC-Fe,W \\
\hline exp & $15.8-16.2$ & $0.9-1.3$ \\
\hline calc & 14.6 & 1.1 \\
\hline
\end{tabular}

Table 1. Comparison of the experimental W/M ratio (exp) in the binder with the equilibrium value at $1000^{\circ} \mathrm{C}$ (calc) calculated with Thermocalc ${ }^{\mathrm{TM}}$ for WC-Ni,W and WC-Fe,W.

\section{Results}

\subsection{General features of WC grains}

TEM investigations were conducted to determine the effect of binder on WC grain shape by observing WC grains along specific lattice directions. In WC-Co alloys, the WC grain morphology is a triangular prism with truncated corners. (0001) basal and $(0,1,-1,0)$ prismatic facets delimit the grains [41]. A similar shape was found for all binders (Fig. 2). A striking feature is the serrated shape of WC grains in WC-Fe,W alloy where numerous steps with nanometric size are observed along WC/Fe interfaces (Fig. 2f). They are related to the grain growth 
process in W-rich alloys: nucleation of new layers would be more rapid than lateral growth of these layers, especially in WC-Fe,W [19].
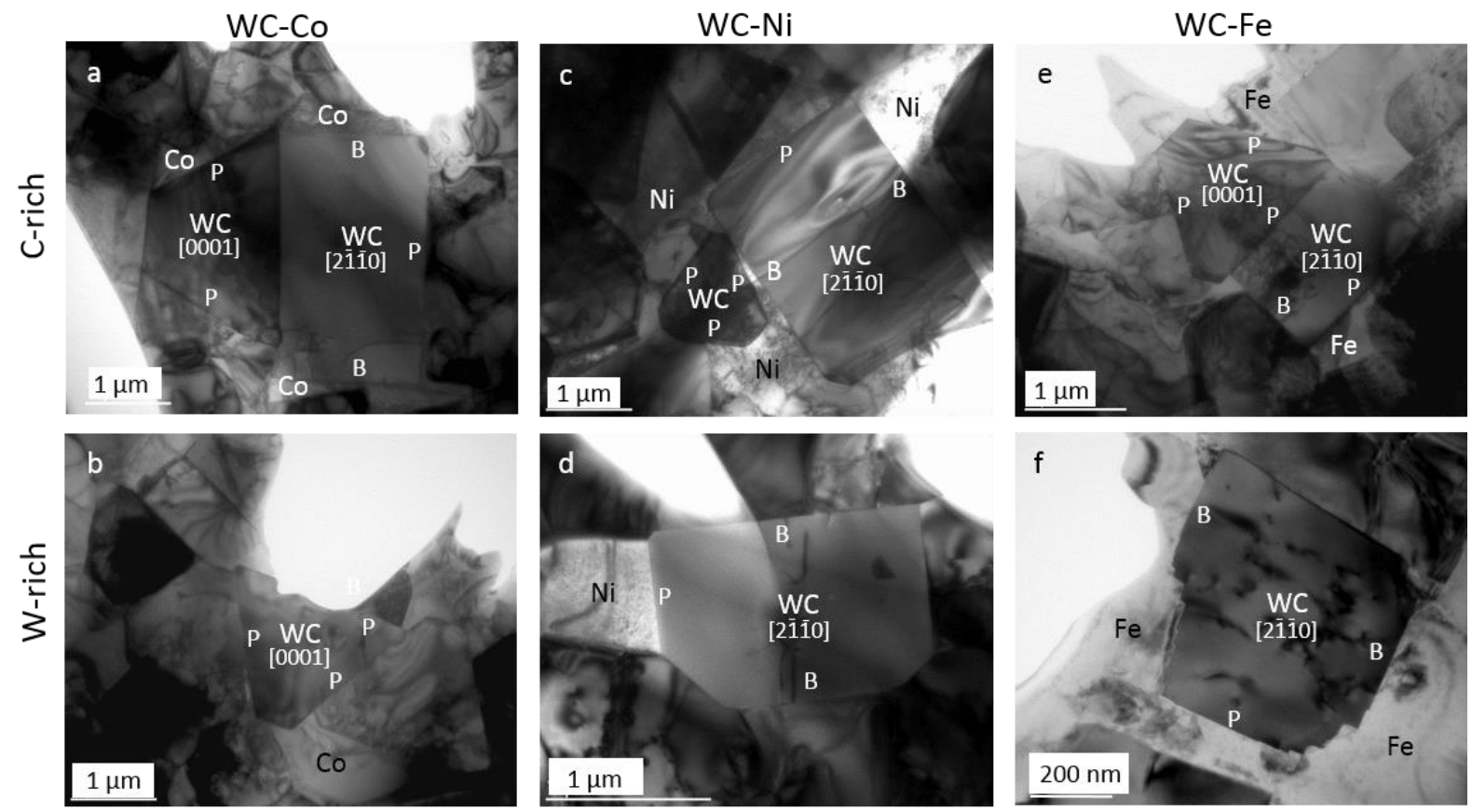

Figure 2. General shape of WC grains in C-rich and W-rich cemented carbides with (a,b) Co, (c,d) Ni and (e,f) Fe as a binder. WC grains are observed along $[0,0,0,1]$ or $[2,-1,-1,0]$ zone axis to evidence $(0,1,-1,0)$ prismatic $(P)$ and $(0,0,0,1)$ basal $(B)$ facets.

\subsection{Preferred orientation relationships at $\mathrm{WC} /$ binder interfaces}

After sintering, the Co based binder has the FCC crystalline structure in WC-Co alloys and the following orientation relationship (OR) between Co and basal facets of WC is sometimes observed:

Such OR was previously noted for Co inclusions in WC grains [42]. In WC-Co alloys, it is particularly observed for small Co pools at the corners between WC grains in the liquid phase sintered alloys $[43,44]$. It forms during cooling of the alloys. It is also very frequently found at basal interfaces after solid state sintering owing to a recrystallization process $[44,45]$. As the parametric misfit is about $15 \%$, the interface contains a high density of misfit dislocations and the interface is semi-coherent $[44,46]$. No preferred orientation is observed on the prismatic planes of WC grains. Similar OR was found for WC-Ni alloys in this work with Ni also having the FCC structure (Fig. 3). Owing to the small difference between the lattice parameter of Co and Ni binder ( $a=0.3544$ $\mathrm{nm}$ for pure Co, $\mathrm{a}=0.3524 \mathrm{~nm}$ for pure $\mathrm{Ni}$ ), the parametric misfit occurring at the basal interface is of the same order. 


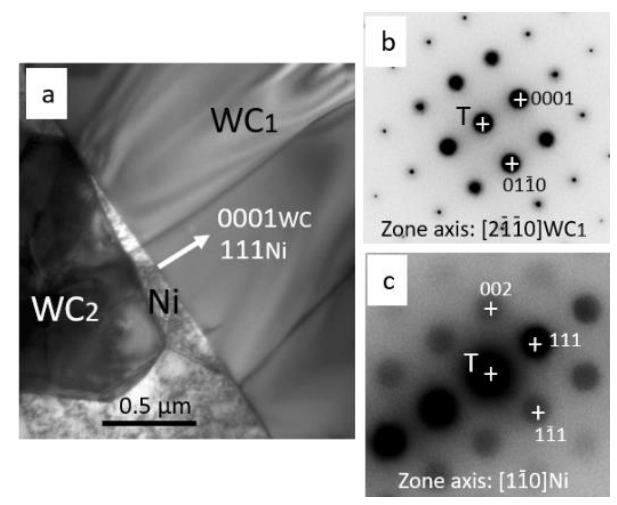

Figure 3. Preferred orientation of Ni binder found at the basal facet of WC grains in WC-Ni,C alloy. (a) Only the small pool of Ni located between two WC grains adopts a special OR with the WC grain called WC $\mathrm{C}_{1}$. (b) Corresponding electron diffraction pattern of $\mathrm{WC}_{1}$ grain, (c) of $\mathrm{Ni}$.

However, this OR is not found in WC-Fe alloys as Fe binder has a body-centred cubic (BCC) crystalline structure after cooling ( $\mathrm{a}=0.287 \mathrm{~nm}$ for pure Fe). By contrast, an epitaxy orientation with prismatic facets of WC grains occurs according to the relation (Fig. 4):

To observe this epitaxy relationship by TEM, WC grains were oriented along $<0001>0 \mathrm{r}<2,-1,-1,0>$ directions. Among the 17 grains studied in this work in WC-Fe carbides, the epitaxy was found for 15 grains. In some cases, only a thin layer of binder adjacent to a prismatic facet was found to have the epitaxy orientation. It seems there is no effect of carbon content on the occurrence of the epitaxy. Its high frequency is probably due to the small parametric misfit at the interface $(<1.5 \%)$ which favours the formation of epitaxial nuclei of Fe in contact with prismatic facets upon cooling (Fig.4f). 

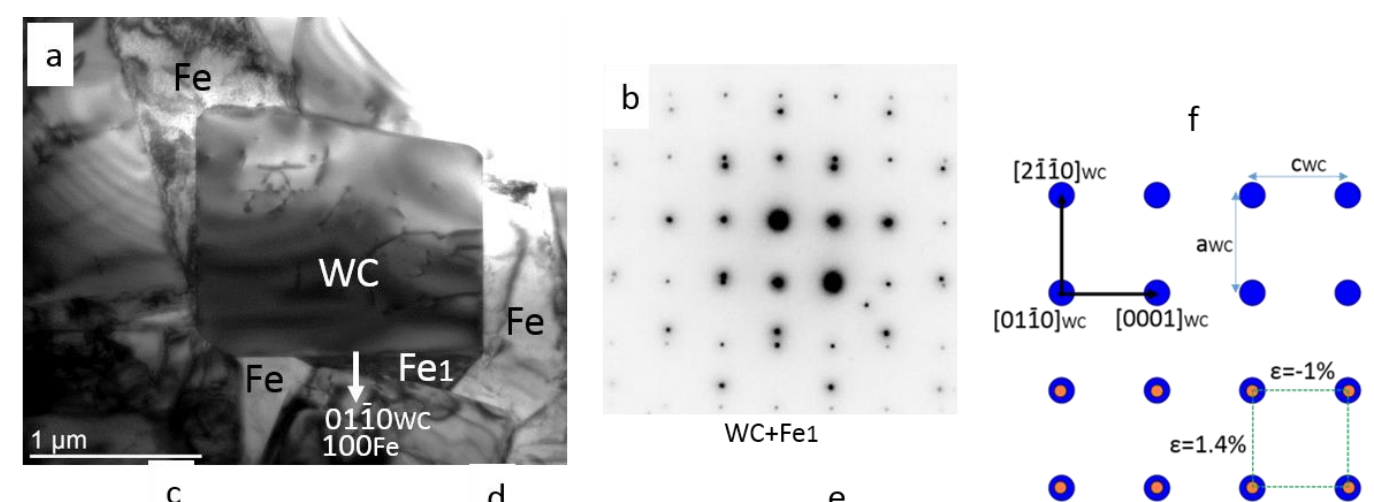

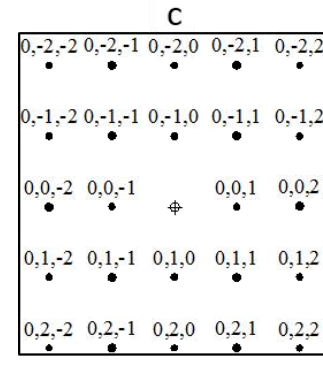

[21̄10]WC

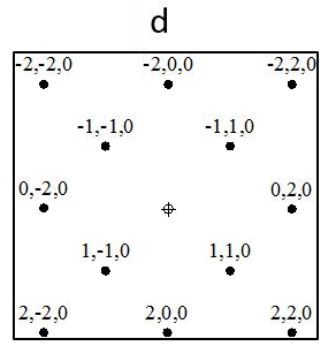

[001]Fea

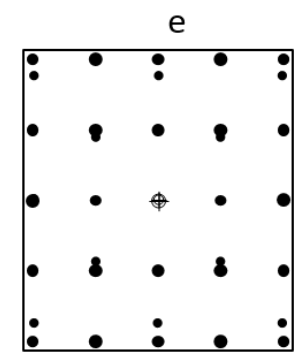

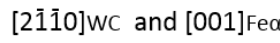

Figure 4. Epitaxy orientation of Fe binder at a prismatic facet of a WC grain in WC-Fe, C alloy. (a) General image of a WC grain surrounded by Fe and (b) diffraction pattern obtained by selecting WC grain and Fe1 binder pool. (c,d) Diffraction patterns of WC and Fe simulated with Carine ${ }^{\mathrm{TM}}$ software according to the experimental crystallographic orientations and (e) simulation of (b). (f) Atomic positions in the WC/Fe interface plane showing the good fit between the crystal lattices.

\subsection{Grain boundary segregation}

Among the grain boundary population in WC-Co alloys, about 10 to $20 \%$ correspond to the low $\Sigma=2$ coincidence site lattice (CSL) grain boundary, depending on the Co content $[47,48]$. The orientation relationship of these grain boundaries is close to $90^{\circ}[1,0,-1,0]$, and they mainly have a twist character, with the boundary parallel to the $(1,0,-1,0)$ plane. In this work, these special grain boundaries were analysed in WC-Co and WC-Ni alloys, not in WC-Fe carbides although they also exist in these alloys, for comparison with literature results (Fig. 5). In all cases, no binder segregation was detected in $\Sigma=2$ grain boundaries whatever the carbon content in the alloy. 

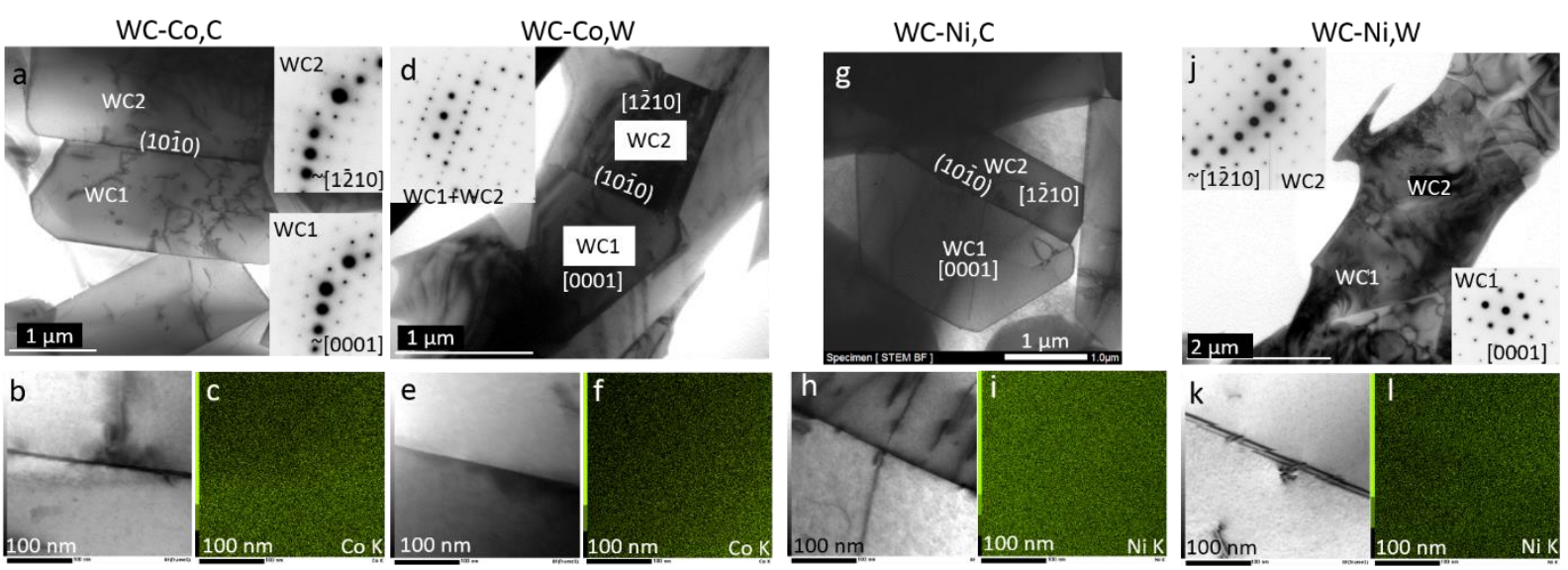

Figure 5. Examples of $\sum=2$ grain boundaries in $W C-C o, C(a-c), W C-C o, W(d-f), W C-N i, C(g-i), W C-N i, W(j-I)$. The general image of the grain boundaries and the associated diffraction patterns are shown in $a, d, g$, j. The analysed area are shown in (b, e, h, k) and the corresponding elemental maps for Co or $\mathrm{Ni}$ are displayed in $(c, f, I, I)$.

In almost all other grain boundaries, binder atoms are present. Examples of grain boundary segregation in WCCo alloys are shown in Fig. 6. A Co enrichment is detected at the grain boundary in each alloy. Calculation of the segregation width according to eq. 1 for these examples gives a value of $0.23 \mathrm{~nm}$ in WC-Co,C and $0.18 \mathrm{~nm}$ in WC-Co,W.
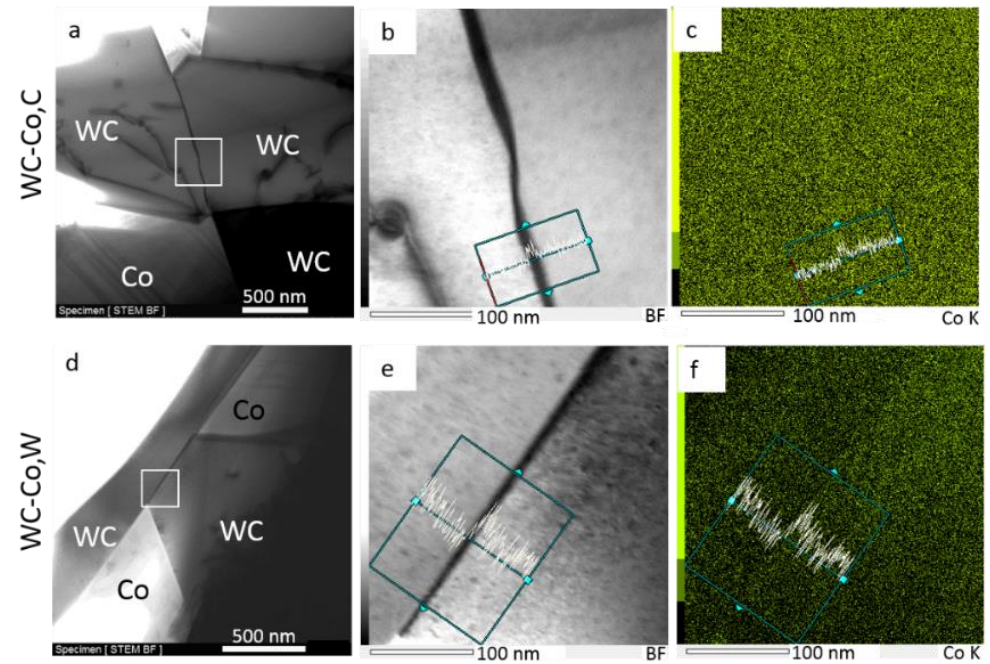

Figure 6. STEM/EDS images of grain boundaries in WC-Co,C (a-c) and in WC-Co,W (d-f). (a, d) General images of the grain boundaries where the white square delineates the studied area $(b, e)$, profile of the Co intensity across the boundary and $(c, f)$ elemental map for Co showing the Co enrichment at the grain boundary.

Similar analyses were carried out in the alloys with $\mathrm{Ni}$ binder. Ni enrichment is observed in all but $\sum=2$ grain boundaries. Figure 7 displays examples for WC-Ni,C and WC-Ni,W alloys. A segregation width of $0.19 \mathrm{~nm}$ is calculated for the grain boundary of the figure in WC-Ni,C and $0.28 \mathrm{~nm}$ in WC-Ni,W. 



Figure 7. STEM/EDS images of grain boundaries in WC-Ni,C (a-c) and in WC-Ni,W (d-f). (a,d) General images of the grain boundaries where the white square delineates the studied area $(b, e)$, profile of the Ni intensity across the boundary and $(c, f)$ elemental map for Ni showing the Ni enrichment at the grain boundary.

Finally, analyses were conducted in cemented carbides with Fe binder. $\Sigma=2$ grain boundaries were not studied in these alloys. Fe enrichment was found in all analyzed grain boundaries. In the examples of Fig. 8, a segregation width of $0.33 \mathrm{~nm}$ is calculated for the grain boundary in WC-Fe,C and $0.09 \mathrm{~nm}$ in WC-Fe,W.
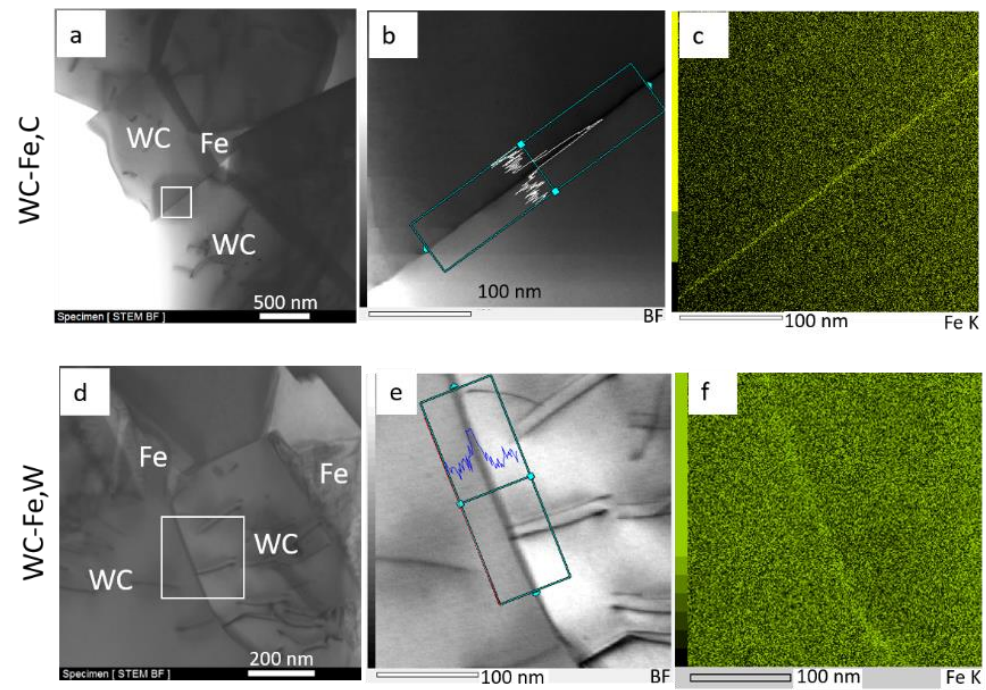

Figure 8. STEM/EDS images of grain boundaries in WC-Fe,C (a-c) and in WC-Fe,W (d-f). (a,d) General images of the grain boundaries where the white square delineates the studied area $(b, e)$, profile of the Ni intensity across the boundary and $(c, f)$ elemental map for Fe showing the Fe enrichment at the grain boundary.

The results are summarized in Fig. 9 to compare the alloys. A mean segregation width of $0.17 \mathrm{~nm}$ and $0.13 \mathrm{~nm}$ is found for WC-Co,C and WC-Co,W, 0.22 and $0.25 \mathrm{~nm}$ for WC-Ni,C and WC-Ni,W and 0.41 and $0.33 \mathrm{~nm}$ for WC- 
Fe, C and WC-Fe,W, respectively. Using the spacing between $(1,1,1)$ planes as the thickness of one monolayer $\left(d_{(111)}=205 \mathrm{~nm}, 0.203,0.209 \mathrm{~nm}\right.$ for Co, Ni and Fe, respectively) leads to 0.8 and 0.6 ML for WC-Co,C and WCCo,W, 1.1 and 1.2 ML for WC-Ni,C and WC-Ni,W and 2 and 1.7 ML for WC-Fe,C and WC-Fe,W, respectively.


Figure 9. (a) Calculated segregation widths deduced from EDS/STEM measurements for the studied grain boundaries, (b) mean thickness value (in ML unit) and standard deviation found for all alloys. $\Sigma=2$ grain boundaries are not included in the graphs.

\section{Discussion}

Regarding the grain boundary segregation, WC-Co alloys are first considered for comparison with literature. No effect of carbon content is found in agreement with DFT calculations. The segregation width measured in the present work (0.6-08 ML) is in good agreement with previous experimental studies, especially carried out by APT $[27,28]$ as well as by atomistic modelling $[49,23]$. Also, no segregation is detected in the special $\Sigma=2$ grain boundary as predicted by calculations [50]. It can be observed that although the analyses are not fully quantitative, the method leads to valid estimates of the segregation in grain boundaries.

Using alternative binders, no effect of $\mathrm{C}$ content is detected for $\mathrm{Ni}$ and Fe binder as for $\mathrm{Co}$. The Fe segregation ( 1.5-2 ML) seems to be slightly higher than Ni segregation ( $1 \mathrm{ML})$, which is slightly higher than Co segregation. There is no other experimental or calculated data for Fe. “. For $\mathrm{Ni}$, the measured segregation is slightly higher than the calculated value (0.5 ML) [31]. Owing to the small number of analyzed grain boundaries in this work and approximations of the analysis method used, further characterization especially by a more sensitive technique as APT would be necessary to confirm these results. This study concludes to a binder segregation in carbide grain boundaries for all binders, independently of the carbon content. The present measurements confirm the existence of binder segregation with a thickness around one monolayer and 
therefore of a continuous carbide skeleton in the material whatever the binder, rather than nanometric segregation layers sometimes reported. Among the investigated alloys, the microstructure of WC-Fe carbides is different in two points. First, the grain boundary segregation is slightly higher, second, a significant amount of coherent WC/binder interfaces are found in these alloys. Both could have an influence on their mechanical properties. Segregation could facilitate grain boundary sliding at high temperature and consequently permit higher deformation of the carbide skeleton upon stress. Moreover, coherency between carbide and binder phase could enhance the strength of these materials [33]. Further investigations would be helpful to study these specific effects.

\section{Conclusions}

The microstructure of cemented carbides with $\mathrm{Co}$, Ni or Fe binder was studied by TEM and STEM/EDS in W-rich and C-rich alloys. Special attention was given to WC/Co interface coherency and to WC/WC grain boundary composition.

(1) In all alloys, WC grain shape is rather faceted with habit planes parallel to the prismatic and basal planes of WC. A high density of nanometric steps is found at WC/Fe interfaces in the W-rich WC-Fe alloy.

(2) Semi-coherent interfaces are occasionally found between basal facets of WC and Ni binder with the same orientation relationship as previously observed for Co binder. For Fe binder, numerous coherent interfaces form at prismatic facets of WC grains. Comparing the alloys, it can be speculated that the high amount of coherent interfaces in WC-Fe alloys could be beneficial to the strength of the material.

(3) The grain boundary segregation was studied using a semi-quantitative approach allowing the segregation width to be estimated. No binder segregation was detected in grain boundaries with $\Sigma=2$ orientation. Outside these boundaries, in all alloys, the mean segregation width is lower than $0.4 \mathrm{~nm}(2 \mathrm{ML})$. No effect of carbon content in the alloy was observed. Comparison between segregation levels gives the highest value for Fe and the lowest for Co. The present results confirm the existence of the WC skeleton whatever the binder investigated in this work. The slightly higher segregation level with Fe could give the grain boundaries some different properties which should be evaluated.

\section{Acknowledgments}

The authors are grateful to Sandvik Coromant R\&D, Stockholm, Sandvik Mining and Rock Technology, R\&D Rock Tools, Stockholm and Seco Tools AB, Fagersta, Sweden for their financial and technical support, for provision of powder mixtures and for fruitful discussions about experimental results. STEM/EDS was performed at the CMTC characterization platform of Grenoble INP, supported by the Centre of Excellence of Multifunctional Architectured Materials "CEMAM" n ANR-10-LABX-44-01 funded by the "Investments for the Future" Program. G. Renou is acknowledged for his help at the 2100F JEOL microscope. 


\section{References}

[1] Scholl H, Hofman B, Rauscher A. Anodic polarization of cemented carbides of the type [(WC,M): $M=\mathrm{Fe}, \mathrm{Ni}$ or Co] in sulphuric acid solution. Electrochimica Acta. 1992;37:447-52.

[2] Gille G, Bredthauer J, Gries B, Mende B, Heinrich W. Advanced and new grades of WC and binder powder their properties and application. Int. J. Refract. Met. Hard Mater. 2000;18:87-102.

[3] https://echa.europa.eu/fr/substance-information/-/substanceinfo/100.028.325

[4] Norgren S, Garcia J, Blomqvist A, Yin L. Trends in the P/M hard metal industry. Int. J. Refract. Met. Hard Mater. 2015;48:31-45.

[5] Almond EA, Roebuck B. Identification of optimum binder phase compositions for improved tungsten carbide hard metals. Mater Sci Eng, A. 1988;A105-106:237-48.

[6] Tracey VA. Nickel in hardmetals. Int. J. Refract. Met. Hard Mater. 1992;11:137-49.

[7] Prakash L. A review of the properties of tungsten carbide hardmetals with alternative binder systems. In: Bildstein H. and Eck R., Editors. 13th International Plansee Seminar. Reutte, Tirol 1993. p. 80-109.

[8] Guillermet A. An Assessment of the Fe-Ni-W-C Phase Diagram. Zeitschrift für Metallkunde. 1987;78:165-71.

[9] Uhrenius B, Pastor H, Pauty E. On the composition of Fe-Ni-Co-WC-based cemented carbides. Int. J. Refract. Met. Hard Mater. 1997;15:139-49.

[10] Fernandes CM, Senos AMR. Cemented carbide phase diagrams: A review. Int. J. Refract. Met. Hard Mater. 2011;29:405-18.

[11] Schubert WD, Fugger M, Wittmann B, Useldinger R. Aspects of sintering of cemented carbides with Febased binders. Int. J. Refract. Met. Hard Mater. 2015;49:110-23.

[12] Fernandes CM, Senos AMR, Vieira MT, Antunes JM. Mechanical characterization of composites prepared from WC powders coated with Ni rich binders. Int. J. Refract. Met. Hard Mater. 2008;26:491-8.

[13] Fernandes CM, Vilhena LM, Pinho CMS, Oliveira FJ, Soares E, Sacramento J, et al. Mechanical characterization of WC-10wt\% AISI 304 cemented carbides. Mater. Sci. Eng. A. 2014;618:629-36.

[14] Ezquerra BL, Lozada L, van den Berg H, Wolf M, Sánchez JM. Comparison of the thermal shock resistance of WC based cemented carbides with Co and Co-Ni-Cr based binders. Int. J. Refract. Met. Hard Mater. 2018;72:8996.

[15] Gao Y, Luo B-H, He K-J, Zhang W-W, Bai Z-H. Effect of Fe/Ni ratio on the microstructure and properties of WC-Fe-Ni-Co cemented carbides. Ceram. Int. 2018;44:2030-41.

[16] de Oro Calderon R, Agna A, Gomes UU, Schubert W-D. Phase formation in cemented carbides prepared from WC and stainless steel powder - An experimental study combined with thermodynamic calculations. Int. J. Refract. Met. Hard Mater. 2019;80:225-37. doi.org/10.1016/j.ijrmhm.2019.01.012

[17] de Oro Calderon R, Edtmaier C, Schubert W-D. Novel binders for WC-based cemented carbides with high $\mathrm{Cr}$ contents. Int. J. Refract. Met. Hard Mater. 2019;85:105063. doi.org/10.1016/j.ijrmhm.2019.105063

[18] Wittmann B, Schubert W-D, Lux B. WC grain growth and grain growth inhibition in nickel and iron binder hardmetals. Int. J. Refract. Met. Hard Mater. 2002;20:51-60. 
[19] Roulon Z, Missiaen JM, Lay S. Carbide grain growth in cemented carbides sintered with alternative binders. Int. J. Refract. Met. Hard Mater. 2020,86:105088. doi.org/10.1016/j.ijrmhm.2019.105088

[20] Sigl LS, Exner HE. Experimental study of the mechanics of fracture in WC-Co alloys. Met. Trans. A. 1987;18:1299-308.

[21] Tarragó JM, Jiménez-Piqué@ E, Schneider L, Casellas D, Torres Y, Llanes L. FIB/FESEM experimental and analytical assessment of R-curve behavior of WC-Co cemented carbides. Materials Science and Engineering: A 645:142-149.

[22] Tarragó JM, Ferrari C, Reig B, Coureaux D, Schneider L, Llanes L. Mechanics and mechanisms of fatigue in a WC-Ni hardmetal and a comparative study with respect to WC-Co hardmetals. International Journal of Fatigue $70: 252-25$

[23] Petisme MVG, Johansson SAE, Wahnström G. A computational study of interfaces in WC-Co cemented carbides. Modelling Simul Mater Sci Eng. 2015; 23:045001.

[24] Sharma NK, Ward ID, Fraser HL, Williams WS. STEM Analysis of Grain Boundaries in Cemented Carbides. J. Am. Ceram. Soc. 1980;63:194-6.

[25] Jayaram V, Sinclalr R. Detection of Thin Intergranular Cobalt Layers in WC-Co Composites by Lattice Imaging. J. Am. Ceram. Soc. 1983;66:C-137-C-139.

[26] Friederich KM. Cobalt enrichment at tungsten carbide grain boundaries in hardmetals. Met. Sci. $1983 ; 17: 456-8$

[27] Henjered A, Hellsing M, Andren HO, Norden H. Quantitative microanalysis of carbide/carbide interfaces in tungsten carbide-cobalt-base cemented carbides. Mater Sci Technol. 1986;2:847-55.

[28] Weidow J, Andrén H-O. Grain and phase boundary segregation in WC-Co with TiC, ZrC, NbC or TaC additions. Int. J. Refract. Met. Hard Mater. 2011;29:38-43.

[29] Vicens J, Benjdir M, Nouet G, Dubon A, Laval JY. Cobalt intergranular segregation in WC-Co composites. J. Mater. Sci. 1994;29:987-94.

[30] Konyashin I, Zaitsev AA, Sidorenko D, Levashov EA, Ries B, Konischev SN, et al. Wettability of tungsten carbide by liquid binders in WC-Co cemented carbides: Is it complete for all carbon contents? Int. J. Refract. Met. Hard Mater. 2017;62:134-48.

[31] Gren MA, Wahnström G. Wetting of surfaces and grain boundaries in cemented carbides and the effect from local chemistry. Materialia. 2019;8:100470. doi.org/10.1016/i.mtla.2019.100470

[32] Liu X, Song X, Wang H, Liu X, Tang F, Lu H. Complexions in WC-Co cemented carbides. Acta Mater. 2018;149:164-78.

[33] Song X, Gao Y, Liu X, Wei C, Wang H, Xu W. Effect of interfacial characteristics on toughness of nanocrystalline cemented carbides. Acta Mater. 2013;61:2154-62.

[34] Bounhoure V, Lay S, Loubradou M, Missiaen JM. Special WC/Co orientation relationships at basal facets of WC grains in WC-Co alloys. J. Mater. Sci. 2008;43 (3):892-9

[35] Christensen M, Wahnström G, Lay S, Allibert CH. Morphology of WC grains in WC-Co alloys: Theoretical determination of grain shape. Acta Mater. 2007;55:1515-21. 
[36] Ikeda JAS, Chiang Y-M, Garratt-Reed AJ, Sande JBV. Space Charge Segregation at Grain Boundaries in Titanium Dioxide: II, Model Experiments. J. Am. Ceram. Soc. 1993;76:2447-59.

[37] Gu H, Cannon RM, Rühle M. Composition and chemical width of ultrathin amorphous films at grain boundaries in silicon nitride. J. Mater. Res. 1998;13:376-87.

[38] Weidow J, Johansson S, Andrén H-O, Wahnström G. Transition Metal Solubilities in WC in Cemented Carbide Materials. J. Am. Ceram. Soc. 2011;94:605-10.

[39] Williams DB, Carter CB. Transmission Electron Microscopy. Spectroscopy IV. New York: Plenum Press; 1996.

[40] Haglund S, Ägren J. W content in Co binder during sintering of WC-Co. Acta Mater. 1998;46:2801-7.

[41] Exner HE. Physical and Chemical Nature of Cemented Carbides. Int. J. Met. Rev. 1979;4:149-73.

[42] Mohan K, Strutt PR. Microstructure of spray converted nanostructured tungsten carbide-cobalt composite. Mater Sci Eng A. 1996;209 (1-2):237-242

[43] Lay S, Allibert CH, Christensen M, Wahnström G. Morphology of WC grains in WC-Co alloys. Mater Sci Eng A. $2008 ; 486: 253-261$

[44] Bounhoure V, Missiaen J-M, Lay S, Pauty E. Discussion of nonconventional effects in solid-state sintering of cemented carbides. J Am Ceram Soc. 2009;92 (7):1396-1402

[45] Bounhoure V, Lay S, Charlot F, Antoni-Zdziobek A, Pauty E, Missiaen JM. Effect of C content on the microstructure evolution during early solid state sintering of WC-Co alloys. Int. J. Refract. Met. Hard Mater. 2014;44 (0):27-34

[46] Priester L. Grain boundaries: from theory to engineering. Berlin: Springer; 2013.

[47] Pellan M, Lay S, Missiaen J-M, Norgren S, Angseryd J, Coronel E, et al. EBSD study to analyse mechanisms of phase boundary and grain boundary development in WC-Co cemented carbides. Powder Met. 2017;60:20815.

[48] Pellan M, Lay S, Missiaen J-M, Norgren S, Angseryd J, Coronel E, et al. A new insight into the $\Sigma=2$ grain boundary characteristics in WC powder and in WC-Co sintered materials. Acta Mater. 2018;155:372-8.

[49] Christensen M, Wahnström G. Effects of cobalt intergranular segregation on interface energetics in WC-Co. Acta Mater. 2004;52:2199-207.

[50] Johansson SAE, Petisme MVG, Wahnström G. A computational study of special grain boundaries in WC-Co cemented carbides. Computational Mater. Sci. 2015;98:345-53. 